\title{
College men's fashion: clothing preference, identity, and avoidance
}

\author{
Mijeong Noh", Meng Li ${ }^{\dagger}$, Kaleb Martin ${ }^{\dagger}$ and Joseph Purpura ${ }^{\dagger}$
}

\author{
*Correspondence: \\ noh@ohio.edu \\ ${ }^{\dagger}$ Meng Li, Kaleb Martin and \\ Joseph Purpura contributed \\ equally to this research \\ Department of Human \\ and Consumer Sciences, \\ Ohio University, Athens, USA
}

\begin{abstract}
The goal of our exploratory study was to investigate what fashion means to college men in terms of preference, identity, and avoidance. Specifically, we aimed to determine what young men want to achieve as well as avoid through their clothing. We interviewed 15 college men to collect data. This exploratory study revealed that the male college students who participated in this study desire clothing that is comfortable, gives them confidence, and meets the expectations of their surroundings. The results suggest that college men's fashion preferences are driven largely by a desire for comfort and adherence to norms. Moreover, the study participants avoided certain types of clothing due to the clothing's incongruence with their styles. Their aversion to clothing that could be perceived as alternative, gangster, or gay indicates that these men strived to avoid clothing that conveys identities viewed as non-conformist, nonprofessional, or unusual. In line with our findings, we encourage universities to educate students in order to prevent them from holding negative stereotypes against African Americans and homosexuals. Continued educational efforts could be made through courses that curtail aversion to underrepresented ethnic groups.
\end{abstract}

Keywords: College men, Fashion, Identity, Avoidance

\section{Introduction}

A brief review of the literature on the social psychology of clothing reveals that young women are more frequently research participants than men (Kwon 1997; Kaiser 1997; Crane 2000). This may be because women far outnumber men in majoring in clothing design and apparel merchandising and thus are more easily accessible as research participants than men. Regardless of why clothing research includes more women as research participants, this focus on women has resulted in a dearth of research on young men. In support of this, Reilly and Rudd (2007) report that research has investigated men's clothing preferences and habits to a lesser extent than women's. With rare exceptions (e.g., Frith and Gleeson 2004; Hathcote and Kim 2008), men's ideas about fashion and its importance in their lives have been overlooked. Despite the limited research on young men, consumer groups comprised of college men are important to commercial marketers in terms of expenditure in men's apparel and accessories. According to Statista, in 2012 the expenditure on men's clothing goods in the United States was $\$ 22.2$ billion. Men purchased footwear the most, followed by shirts and suits. Prior research has also

(C) 2015 Noh et al. This article is distributed under the terms of the Creative Commons Attribution 4.0 International License (http:// creativecommons.org/licenses/by/4.0/), which permits unrestricted use, distribution, and reproduction in any medium, provided you give appropriate credit to the original author(s) and the source, provide a link to the Creative Commons license, and indicate if changes were made. 
shown that men's interest in fashion is on the rise, leading to an increase in men's apparel sales (Bakewell et al. 2006; Frith and Gleeson 2004).

Historically, women have been much more conscious about their appearance than men, but in recent times there appears to have been a change in this level of focus on appearance among men. Specifically, young men in Generation $Y$ who have been socialized by mass media and marketing activities have become appearance conscious, which leads to apparel consumption (Kacen 2000; Patterson and Elliot 2002). Young men usually use dress to communicate their identities (Shete 2012), and their aspirations toward communicating this may influence their apparel consumption (Kang et al. 2011). Understanding the relationship between college-aged men's identities and their clothing choices provides apparel marketers with useful information to develop effective strategies to produce and market clothes in accordance with the common values with which this group strives to identify.

According to Hogg and Banister (2001), individuals can either have a positive reference point (i.e., desired end state) or a negative reference point (i.e., undesired end state) that they use to achieve their desired identities. So far, much research has been conducted on the positive aspects of consumers' consumption choice. A lack of research into the negative aspects of consumption choice motivated us to question their impact on consumer behavior. Consumers' avoidance behavior allows them to create further distance between themselves and their undesired identities (Hogg and Banister 2001), staying within the threshold of their desired identities. Thus, this research focuses on the clothing and style that college men avoid. An exploratory study was conducted on men attending a major midwestern university. On the basis of the results of the exploratory study, research interview questions for any further studies will be modified to address the research problem appropriately.

The purpose of the exploratory study was to investigate what clothing college men prefer, what identities they achieve through their clothing, and what they want to avoid in their clothing choices. Our research questions were as follows: (1) Does college-aged men's clothing reflect their identities and what do they want to express through their clothing choices? and (2) What undesired identities (related to aspects of an avoided self) do college-aged men avoid in their clothing choices?

\section{Literature review Social identity theory}

Social identity theory as conceptualized by Tajfel and Turner (1979) refers to perceived identity of the groups to which people belong (Tajfel 1982). Social identity theory posits that a person's self-concept is based on his or her group membership. This theory consists of two dimensions: social identity and personal identity (Howard 2000; Tajfel 1982). Social identity reflects membership in various social groups (e.g., clubs, social class), and personal identity represents the unique attributes that differentiate one person from another (Howard 2000; Tajfel 1982). In complex social environments, young people can use their identification with in-groups (i.e., their own group) versus out-groups (i.e., other groups) (Ogilvie 1987) to align their appearance (i.e., the total and composite image created by clothing) with a desired social group and to differentiate themselves 
from the undesired, or avoidance, reference group (Banister and Hogg 2004). Thus, social identities provide status to young men and enhance their self-esteem.

Research has used social identity theory to investigate the effects of men's identities on the use of dress (i.e., all material objects added to body). For example, Kang et al. (2011) used social identity theory as a theoretical framework to investigate the relationship between young professional men's perceptions of work identity and their use of dress. They found that the young men who felt incomplete in their work identity used dress as a symbol to construct their identities. Thus, in this study, we used social identity theory as a theoretical foundation to examine the relationship between college men's identities and their clothing choices.

\section{Men's identities with fashion}

According to Kratz and Reimer (1998), fashion is filled with meanings and symbols, through which people can visually communicate with one another in a rapid and direct manner. Fashion enables people to express their views about themselves and their identities through the use of clothing; it allows them to visually communicate who they are, who they want to be, what type of social group they want to belong to, and whom they do not want to be associated with the most (Shete 2012). Furthermore, Bennett (2005) states that fashion is one of the channels through which people can most readily give voice to their identities. Beyond words, people can convey themselves through dress and fashion, thus creating their social identity. Fashion's essential role in providing people with means to build, shape, and communicate their identities is especially prominent in larger metropolitan cities where they "mingle with crowds of strangers and have only fleeting moments to impress them" (Bennett 2005, p 96).

Men identify themselves through various ways. For example, some men may identify themselves through their body appearance, while others may show their identities by the way they dress; Hathcote and Kim (2008) note that men represent themselves through how they dress. Moreover, many men care about what they wear and how they wear it on a daily basis and also care about how others perceive them. As part of campus society, college students also spend time on how they dress. Some male students prefer wearing sweatpants or baggy basketball shorts at school, while others prefer wearing polo shirts and casual pants. The way male college students choose their outfits for school represents their different personalities and identities. For example, some male students wear athletic clothing to show off their masculinity. This is consistent with Lunceford (2010, p. 66), who argues that "male students choose a specific article of clothing because of how it makes them feel or because it downplays what they consider to be unattractive aspects of their bodies while accentuating their best features."

Researchers have conducted studies related to the importance of clothing and fashion for identity creation and communication. For example, Piacentini and Mailer (2004) found that young people in the United Kingdom tended to use clothing to show similarity between themselves and the groups they wished to be identified with, and as a channel to establish potential friendships. Schofield and Schmidt (2005) examined the importance of clothes used in constructing and communicating gay men's personal and group identities with a sample of Manchester-based respondents. They shaped individual gay identity through different levels (i.e., community level, neo-tribal level, and 
situational level) and found that gay identity emerged through clothing choices. In their study, gay identity is shared on a gay community level to express "gayness" to others; on a neo-tribal level to show "belonging" to a social gay cohort with shared experience and emotions; and on a situational level to make themselves blend in with wherever they are (Schofield and Schmidt 2005).

As mentioned previously, young people in complex social environments can use their identification with in-groups versus out-groups (Ogilvie 1987) to align their appearance with a desired social group, and to differentiate themselves from the undesired, or avoidance, reference group (Banister and Hogg 2004). In their study of a sample of British consumers, Banister and Hogg (2004) found that many consumers wore safe clothing items (e.g., simple clothes, which would be interpreted positively) to avoid censure rather than risky items. If such fears of folly and negative attention are present in male consumers, certain commonalities among them can be identified. Eisler and Skidmore (1987) proposed that men's gender-role expectations contributed to fears about lack of athleticism, emotional intimacy, intimacy with other men (or homophobia), and failure. If the feminine, unathletic, impotent man is representative of perceived undesirability among men, symbolic identifiers of those traits can be indicative of young men's labeling of avoidance reference groups and the "avoided self." Thus, men's fashion conservatism (i.e., dressing in a masculine way according to social norms) could be partially attributed to the generalized fear of appearing "feminine" (Kimmel 1994).

\section{Methods}

\section{Data collection procedure}

We employed the snowball sampling technique to gain access to 15 respondents at a major midwestern university in the United States. Respondents were asked to answer a series of eight interview questions and demographic characteristic questions. They also read a cover letter asking them to indicate their consent to participate in the research; respondents were not provided with incentives to participate. Interview questions were asked either in person or through electronic communication, depending on the respondents' preferred choice. The interview process lasted 30-40 min. Five respondents were interviewed electronically and ten respondents were face-to-face interviewed. The interview was conducted in English.

\section{Research instrument}

This exploratory study examines what young men want to achieve through their clothing choices and what they want to avoid. We used an interview method to collect data. Researchers typically depend on an in-depth interview strategy when their primary strategy is capturing the deep meaning of individual experiences (Marshall and Rossman 2011). Thus, we chose to carry out one-on-one in-depth interviews in order to gain a deeper understanding of consumer motivations (Brannon 2010). The respondents were college men $(n=15)$ who were interviewed by three master graduate students about their clothing choices (e.g., "Describe the clothing you wear most often and why"), why and how they selected clothing to express their identities (e.g., "Does your clothing express your identity? If yes, how? If no, why?"), and how they avoided certain identities through their clothing choices (e.g., "Do you avoid certain clothing? If yes, what are 
some examples? And why do you choose to avoid them?"). Respondents were also asked demographic questions, such as age, parents' income, major, marital status, country of origin, and ethnic group.

\section{Data analysis}

Audio recordings of the interviews were made by three graduate students and then transcribed. They gathered qualitative data, which we analyzed through descriptive statistics (i.e., frequency and percentage), searching for the common words in each transcript. Using inter-coder agreement, we checked the reliability of the interview data. The intercoder agreement method followed this process: grouping of similar responses into categories; coding of responses into categories; then comparison of the coding done by each of the three graduate students until agreement was achieved.

\section{Results and discussion}

\section{Sample characteristics}

In total, 15 respondents took part in the exploratory study. The median age of participants was 24 years. Parents' income ranged from $\$ 50,000$ to $\$ 69,000$. Ten participants were Caucasian, four were Chinese and one was Filipino American. A total of 13 students were single (see Table 1). The sample composed of college-aged male students in midwestern university in the United States with different ethnic groups was meaningful for our exploratory study as limited studies are currently available.

\section{Clothing preference}

All 15 respondents answered questions about their clothing choice. Content analysis yielded five categories stemming from the question about what type of clothing they wore

Table 1 Sample characteristics

\begin{tabular}{ll}
\hline & Percentage (N= 15) (\%) \\
\hline Age & 33.3 \\
$18-19$ & 0 \\
$20-21$ & 26.7 \\
$22-23$ & 40.0 \\
24 and over & \\
Ethnic group & 66.6 \\
American & 26.7 \\
Chinese & 6.7 \\
Filipino American & \\
Marital status & 86.7 \\
Single & 13.3 \\
Married & \\
Parents' income & 26.7 \\
Under $\$ 30,000$ & 6.7 \\
\$30,000 to $\$ 49,999$ & 40.0 \\
\$50,000 to \$69,999 & 13.3 \\
\$70,000 to $\$ 89,999$ & 0 \\
\$90,000 to \$100,000 & 13.3 \\
\$100,000 and over & \\
\hline
\end{tabular}


most often: casual, classic, fashionable, business casual, and sportswear. Ten respondents (67\%) reported that they wear casual clothing most of the time (e.g., T-shirts and jeans); reasons for wearing this category of clothing included "coziness', 'comfort', and 'unassuming". For the second category (classic clothing), two respondents $(13 \%)$ reported that classic clothing made them feel in style and attractive. In addition, some of respondents noted that they believed classic clothing had relatively higher quality. Three respondents mentioned the other three categories. Not surprisingly, most of the respondents preferred wearing casual clothing on a daily basis.

Respondents were also asked to describe the clothing in which they felt most comfortable; again, four types of clothing were mentioned. Five respondents (33\%) reported feeling most comfortable when they wore casual clothing, such as T-shirts, loose-fitting jeans, and boots. Five respondents (33 \%) also mentioned feeling most comfortable wearing dressy clothing, such as button-down shirts and jackets. Three respondents (20\%) mentioned sportswear, the third type of clothing. Finally, two respondents $(13 \%)$ mentioned businesscasual clothing. In describing the type of clothing they felt most comfortable in, respondents also noted several brands. For example, they reported feeling most comfortable when wearing clothing from the brands Gap, PacSun, and Abercrombie and Fitch. We classified this group of respondents into the casual clothing category. We classified respondents who mentioned the brands J.Crew and H\&M into the dressy clothing group. Several respondents also mentioned two types or two brands in which they felt most comfortable.

The sample groups were also asked to describe the type of clothing that made them feel most confident. Ten respondents (67 \%) reported dressy clothing, such as buttondown shirts and suits. Only three respondents (20\%) reported that wearing casual clothing made them feel most confident; items mentioned in this category included jeans, boots, and T-shirts. Sportswear was the least mentioned category, containing just two respondents (13\%).

According to the data, more college-aged men prefer wearing casual-looking clothing to business-casual clothing or sportswear. Indeed, during the interviews respondents wore casual clothing which "uniformly stressed comfort and practicality" (Clemente 2014, p. 1) more often than sportswear. These findings are consistent with those of Frith and Gleeson (2004), who explored the ways in which young men's subjective feelings about their bodies affected their clothing choices. They argued that practical clothing choice (i.e., comfortable clothes) was valued more greatly than the aesthetic aspects of clothing.

\section{Clothing and identity}

The purpose of the exploratory study was to determine whether we could establish a connection between identity and clothing among the respondents. The respondents clearly used clothing to signal their identity and how they wanted to be identified. For our first question, "Does your clothing represent your identity?" 10 respondents (67 \%) answered "yes," three respondents (20 \%) answered "somewhat," one respondent (7\%) answered "no," and one respondent (7\%) was unsure or did not care. Therefore, the majority of subjects $(87 \%)$ gave a positive response to the question. These responses indicate that young men tend to express their identities through their clothing choices, consistent with the findings of Hathcote and Kim (2008), who found that men's identities were communicated by the way they dressed. 
For our second question, we asked what they wanted their clothing to say about them. We received many different answers, so we were tasked with combining and coding certain words into similar groups. The term "trustworthy" topped the list in terms of what five respondents (33\%) wanted their clothing to reveal about them. Four respondents (27 \%) reported "trend"; these respondents wanted to look "cool" and as a "trendsetter." Another popular term was "sophisticated"; three men $(20 \%)$ used similar words, such as "business look" to describe this. We coded the last three men (20\%) as "undetermined" because the variance in their responses was too broad or could not be categorized. For example, one respondent said, "My basic style I hope leads people to believe that I am responsible, I can be trusted and that flashy isn't my style. My clothing shows that I am grown and established."

Our last question to investigate if the participants connect self-identity with their clothing was, "Does your clothing reflect your interests or hobbies?" As we anticipated, 13 respondents (87 \%) answered "yes," and two (13\%) responded "no." Thus, collegeaged men overwhelmingly show their likes, interests, and hobbies through their clothing choices. Does that mean that all college-aged men who wear sweatpants and ball caps are into sports or are athletes? Perhaps not, but these results help bring to light why they make such clothing choices. Clothing and hobbies can show achievement and help enforce positive self-esteem. For example, as one respondent said, "I oftentimes wear meet shirts from the previous weekend; this shows my running achievements. Or I'll wear Vans; this indicates that I'm easygoing and like that 'Southern California lifestyle.' My clothes indicate I am trendy and 'in-the-know' with my clothing choices." Clothing also served as a channel through which interests could be expressed: "I typically will wear band shirts because to me music is one of the things that I care most about." Another participant responded that, "My external appearance is a great representation of my personality. It reflects how much I value professionalism, friendship, and it also shows my sexuality, my attention to detail, and value of myself," indicating that clothing is a tool for college-aged men to express the values they hold themselves up to, thereby establishing themselves within in their community. These findings are consistent with Hogg and Banister (2001), who found that clothing was a significant aspect in creating college students' individual identities.

\section{Avoidances}

We created two questions in our semi-structured interviews to gauge the levels and traits of respondents' choice of avoidance clothing and styles. Through inter-coder agreement, we reached consensus on the categories of avoided clothing expressed, in addition to the underlying motivation for these aversions. The questions were asked in person or through electronic communication. First, respondents were asked if they avoided certain clothing and, if so, to list some examples. They were also asked why they avoided such clothing. Second, respondents were asked if they avoided any styles of clothing, and if so, why they wanted to avoid being associated with those styles.

The 15 respondents supplied disparate clothing styles and justifications. The three styles or genres of clothing expressed most frequently were "alternative," "gangster," and "gay" styles. These titles represent the culmination of similar terminology and responses that we unified through the coding process. We categorized responses such as "goth," 
"grunge," "dark," and "alternative" as alternative. We categorized word such as "thug," "hip-hop," and "gangster" as gangster. Last, we categorized styles containing the terms "gay" or "homosexual" as gay styles. In short, styles perceived as alternative, gangster, and gay were the most commonly avoided from our sample of 15 college-aged men.

The most common aversion was to alternative style and clothing, with $40 \%$ of respondents mentioning consciously avoiding types of alternative clothing. The second most common aversion was to clothing or styles perceived as "gangster" related, with $27 \%$ of respondents mentioning this clothing style. Finally, the third most prevalent responses regarding clothing or styles pertained to "gay" style, with $20 \%$ of respondents expressing this aversion. The other items respondents mentioned represented a small or negligible prevalence, so we included only the three most common aversions in the analysis.

\section{Aversion to alternative styles}

The aversion to alternative styles was accompanied by several rationales. One respondent said he avoided skinny jeans (often associated with "skater" and "emo" culture) simply "for comfort." Another respondent avoided dark and alternative styles to "avoid negative stigmas" and possible associations with low intelligence related to group think. However, the majority of the respondents who said they avoid alternative styles were unable to explain their aversion. Mentions of dislike of alternative clothing were often supplied first and with little hesitation, suggesting that this is a somewhat automatic and marked dislike for those respondents.

One respondent said he avoids wearing black and looking gothic because his friends do not wear those styles, suggesting a fear of ostracism when wearing alternative clothing. In a similar vein, one respondent included that he "doesn't want to lead people to believe he is dark." A 23-year-old Caucasian respondent, when asked if he avoided any styles of clothing, said: "Gothic stuff for sure, dark clothing or Hot Topic stuff. I don't want to be associated with them and I hate the people that wear that stuff, like spiked belts." This type of sentiment occurred almost exclusively among Caucasian respondents from middle- and upper-middle-class backgrounds. The fear of social scrutiny and ostracism, along with a general stigma regarding alternative and counter-culture, appears to be the most common motivation for avoiding alternative styles.

\section{Aversion to gangster styles}

Gangster styles were mentioned often, and responses often indicated social and racial prejudices, in addition to the fear of social judgment. Many respondents associated "big" and "baggy" clothing with gangster style. Race emerged as a definite component of this aversion. All but one of the respondents who listed gangster style as an avoided style identified as Caucasian. One respondent directly indicted his aversion to wearing clothes "a black person would wear," suggesting that affiliation with the African American culture would be undesirable. Other variants included an aversion to "swag gear" and "thug style." Another respondent even used a variant of a racial slur to express his avoidance of gangster-inflected styles. The respondents supplied little additional justification for avoiding this style, and when asked to expound on their preference, three claimed that they were unable to provide further information. 


\section{Aversion to gay styles}

Three respondents expressed avoiding clothing that could be regarded as "gay." The wearing of skinny jeans, jean shorts, $\mathrm{V}$-neck shirts, or cardigans was perceived as indicative of homosexuality, according to the interview data. The inclusion of these items of clothing specifically indicates an association of form-fitting clothing and low necklines with effeminacy and gay culture. Respondents expressed a desire to represent themselves accurately, and those who claimed to avoid gay-inflected clothing suggested that it was undesirable on the grounds that (1) they disliked gay culture, (2) they wanted to express their heterosexuality, and (3) they wanted to avoid speculation from others that they were homosexual. In this regard, homophobic sentiments, a desire for accurate self-representation, and a fear of social judgment all seemed to be components of these respondents' desire to avoid clothing perceived as being worn by gay men. Another respondent said that he refused to wear any clothing from the "women's section," and though this does not necessary relate to the avoidance of gay style, it does represent an often-related fear of gender-role deviation. Thus, an avoided self and avoidance behavior were important factors in clothing choice, supporting earlier findings from Hogg and Banister's (2001) study in which dislikes and distastes of college men were associated with negative symbolic consumption. This sentiment is demonstrated by another respondent's notion that said, "you know that there are certain things that you don't want to buy because you don't want to project yourself in a negative way" They proposed that a greater understanding of the impact of negative symbolic consumption on consumers' product rejection could help the development of companies' marketing communication strategies.

\section{Cultural background and the avoided self}

Demographics indicated different trends in responses among respondents. The four Chinese men who participated were largely unable to produce responses regarding avoided clothing and styles. One of these respondents said he only avoids clothing that is "too colorful or fashionable" because "it is not his style." Another said he only avoids "hip-hop clothing" because it does not match his serious personality. The other two respondents said that there were no types of clothing or styles they avoided. These sentiments contrast greatly with the responses from American students, all but one of whom listed one or several types of avoided clothing and styles.

Furthermore, the brief elaborations the Chinese students supplied regarding the reason they avoid clothing related to issues of personal identity, with no mention of social or cultural motivations for doing so. This indicates that the avoidance of styles due to fears of social castigation and negative group associations could hold as a phenomenon more prevalent in the United States than in China.

\section{Conclusion}

The college-aged men in this study expressed a desire for clothing that is comfortable, gives them confidence, and meets the expectations of their surroundings. These men recognized that their clothing was one representation of their identities. Thus, the results suggest that college men are driven largely by a desire for comfort and to meet normative expectations. These findings are supported by the supposition that "men 
dress for fit and comfort rather than for style", made by Craik (1994) and confirmed by Bakewell et al. (2006). These attributes for college men's clothing choice seem to be quite different from those for young women, who largely make their choices based on brand (fit, look, and style) (Taylor and Cosenza 2002). The driving force for college men's clothing choice is seemingly functional rather than decorative (Kacen 2000), even if they have become more appearance-conscious. Overall, the positive connection between young men's individual identities and their clothing choices parallels previous research on the relationship between young professional men's perceptions of work identity and their dress choices (Kang et al. 2011), and on the link between young people's clothing choices and the identity of the groups to which they belong (Piacentini and Mailer 2004).

A minority of respondents avoided certain types of clothing because they felt it was incongruent with their styles. Their aversion to clothing that appears to belong to alternative, gangster, or gay styles suggests that these men strived to avoid clothing that implied identities viewed as non-conformist, non-professional, and unusual. These men indicated that their clothing choices were perhaps motivated by a desire to fit in with others. Their aversion to clothing styles that communicated incongruent identities implies that deviations from cultural, class, race, and gender-related norms were undesirable.

\section{Limitation and Implications}

We conducted our exploratory study in a short period of time, which provides opportunity for further in-depth interviews on the topic. The samples were all from the midwestern part of the United States, so the results may not be applicable to all college men in the United States. The sexual orientation of each of the study respondents was not determined, and thus might have had some influence on the data. In addition, different topics related to fashion and college-aged men should be explored, as limited studies are currently available. For example, research could focus on effects of variables such as shopping orientation (e.g., convenience/time consciousness, price consciousness, etc.) on the clothing choice of male college students from different ethnic backgrounds. Such research could help apparel marketers develop strategies targeting the shopping orientation of consumers from different ethnic groups. For more generalizable results, research could be extended to a larger sample representing young college men in both the United States and abroad. In addition, this study only constitutes qualitative research due to the limited sample size, Therefore, research should be conducted using quantitative data to achieve more reliable findings.

This exploratory study provides an initial theoretical contribution to the field of fashion and textiles, through the information gathered on relationships between collegeaged men's identities and their clothing choices. Furthermore, the findings from this study provide apparel marketers with important information, in terms of young college men's clothing preferences and the relationship between their clothing choice and identity. The findings offer guidance to apparel marketers so that they can develop effective strategies to increase sales of new products targeted to young male consumers. Apparel marketers should determine which clothing products are congruent with their targeted men's identities and use this information to develop promotional strategies that entice young college men to purchase their products. Note, however, that the diversity 
composition of the students in the major midwestern university where the interviews were conducted was quite low, which likely had a significant impact on our findings. In line with this, we suggest that universities should consider educating students to prevent them from maintaining negative stereotypes against African Americans and homosexuals. Continued educational efforts could be made through course content to curtail the aversion to unrepresented ethnic groups.

Authors' contributions

$M N, M L, K M$, and JP drafted the manuscript. All authors read and approved the final manuscript.

\section{Competing interests}

The authors declare that they have no competing interests.

Received: 1 June 2015 Accepted: 26 November 2015

Published online: 18 December 2015

\section{References}

Bakewell, C., Mitchell, V. W., \& Rothwell, M. (2006). UK Generation Y male fashion consciousness. Journal of Fashion Marketing and Management, 10(2), 169-180.

Banister, E. N., \& Hogg, M. K. (2004). Negative symbolic consumption and consumers' drive for self-esteem: the case of the fashion industry. European Journal of Marketing, 38(7), 850-868.

Bennett, A. (2005). Culture and everyday life. London: Sage.

Brannon, E. L. (2010). Fashion forecasting (3rd ed.). New York: Fairchild.

Clemente, D. (2014). Dress casual: How college students redefined American style. The University of North Carolina Press. Craik, J. (1994). The Face of Fashion. London and New York: Routledge.

Crane, D. (2000). Fashion and its social agendas: Class, gender and identity in clothing. Chicago: University of Chicago Press

Eisler, R. M., \& Skidmore, J. R. (1987). Masculine gender role stress: scale development and component factors in the appraisal of stressful situations. Behavior Modification, 11, 123-136.

Frith, H., \& Gleeson, K. (2004). Clothing and embodiment: men managing body image and appearance. Psychology of Men and Masculinity, 5(1), 40-48.

Hathcote, J. M., \& Kim, S. (2008). Consumer masculinity behavior among college students and its relationship to selfesteem and media significance. Sexy Roles, 58(7-8), 549-555.

Hogg, M. K., \& Banister, E. N. (2001). Dislikes, distastes and the undesired self: conceptualising and exploring the role of the undesired end state in consumer experience. Journal of Marketing Management, 17, 73-104.

Howard, J. A. (2000). Social psychology of identities. Annual Review of Sociology, 26, 367-393.

Kacen, J. J. (2000). Girrl power and boyyy nature: the past, present and paradisal future of consumer gender identity. Marketing Intelligence and Planning, 18, 345-355.

Kaiser, S. B. (1997). The social psychology of clothing: Symbolic appearances in context (2 ${ }^{\text {nd }}$ ed.). Fairchild Books.

Kang, M., Sklar, M., \& Johnson, K. K. P. (2011). Men at work: using dress to communicate identities. Journal of Fashion Marketing and Management, 15(4), 412-427.

Kimmel, M. S. (1994). Masculinity as homophobia. Retrieved May 15, 2015, from http://faculty.ucc.edu/psysoc-stokes/ masculinity.pdf.

Kratz, C., \& Reimer, B. (1998). Fashion in the face of postmodernity. In A. A. Berger (Ed.), The postmodern presence: Readings on postmodernism in American culture and society (pp. 193-211). Walnut Creek: AltaMira Press.

Kwon, Y. H. (1997). Sex, sex-role, facial attractiveness, social self-esteem and interest in clothing. Perceptual and Motor Skills, 84, 899-907.

Lunceford, B. (2010). Clothes make the person? Performing gender through fashion. Communication Teacher, 24(2), 63-68.

Marshall, C., \& Rossman, G. B. (2011). Designing qualitative research (5th ed.). Thousand Oaks: Sage.

Ogilvie, D. M. (1987). The undesired self: a neglected variable in personality research. Journal of Personality and Social Psychology, 52, 379-385.

Patterson, M., \& Elliot, R. (2002). Negotiating masculinities: advertising and the inversion of the male gaze. Consumption Markets and Culture, 5(3), 231-246.

Piacentini, M., \& Mailer, G. (2004). Symbolic consumption in teenagers' clothing choices. Journal of Consumer Behaviour, 3(3), 251-262.

Reilly, A., \& Rudd, N. (2007). Shopping behavior among gay men: issues of internalized homophobia and self-esteem. International Journal of Consumer Studies, 31(4), 333-339.

Schofield, K., \& Schmidt, R. A. (2005). Fashion and clothing: the construction and communication of gay identities. International Journal of Retail \& Distribution Management, 33(4), 310-323.

Shete, V. (2012). Fashion \& social identity: A cultural phenomenon. Retrieved December 12, 2014, from http://virshete. wordpress.com/2012/07/15/fashion-and-social-identity-a-cultural-phenomenon/.

Statista. Consumer expenditure on men's apparel and accessories in the United States in 2012, by category (in billion US dollars). Retrieved November 15, 2014, from http://www.statista.com/statistics/255467/ us-consumer-expenditure-on-mens-apparel-and-accessories-by-category/.

Tajfel, H. (1982). Social identity and intergroup relations. Cambridge: Cambridge University Press. 
Tajfel, H., \& Turner, J. (1979). An integrative theory of intergroup conflict. The Social Psychology of Intergroup Relations, 33-47.

Taylor, S. L., \& Cosenza, R. M. (2002). Profiling later aged female teens: mall shopping behavior and clothing choice. Journal of Consumer Marketing, 19(5), 393-408.

Submit your manuscript to a SpringerOpen ${ }^{\circ}$ journal and benefit from:

- Convenient online submission

- Rigorous peer review

- Immediate publication on acceptance

- Open access: articles freely available online

- High visibility within the field

- Retaining the copyright to your article

Submit your next manuscript at $\boldsymbol{s p r i n g e r o p e n . c o m ~}$ 